\title{
Risk assessment and prediction of heavy metal pollution in sediment of Biliuhe reservoir
}

\author{
Jian Zhao, Hong-bo Zhenga and Wen-jia Zhou \\ Key Laboratory of Industrial Ecology and Environmental Engineering (MOE), School of Environmental Science and \\ Technology, Dalian University of Technology, Dalian 116024, China.
}

Keywords: Biliuhe reservoir; sediment; heavy metal; ecological risk; risk prediction

\begin{abstract}
The Biliuhe reservoir, which is one of the most important water sources in Dalian, is the "source of life" of Dalian. To explore the characteristics of heavy metal pollution in Biliuhe reservoir, the potential ecological risk of these heavy metal elements were evaluated by two methods, i.e. geo-accumulation index and potential ecological risk index, and the risk values of heavy metals in sediment were predicted one year later in the future by grey forecasting model GM $(1,1)$ and RBF neural network. The comprehensive assessment results showed that the pollution level in the reservoir was slight, $\mathrm{Hg}$ was the primary element with higher ecological risk while $\mathrm{Cu}$ was secondary. The forecasting results indicated that the predicted risk value of $\mathrm{Hg}$ was higher than others. The results were discussed in order to provide the theoretical basis for the management of the reservoir in the future. The models will be used widely in the field of ecological risk assessment of heavy metals in sediment, due to the simplification and maneuverability of them.
\end{abstract}

\section{Introduction}

The sediment pollution is one of the most serious environment problems in water ecosystem[1] and should be attached importance. When heavy metals enter into water body, most of them will be adsorbed by the suspended matters, then sedimentate, and finally move into the sediment[2]. The contents of heavy metals in sediment could reflect the degree of heavy metal pollution in water body and the geochemical behaviors of heavy metals[3]. Therefore, it is necessary to pay more attention to the study of the heavy metal pollution in sediment.

At present, the heavy metal pollution in sediment of reservoirs and other water sources is not widely studied in domestic researches. The researches of the heavy metal pollution mainly focus on the studies in lakes[4,5], rivers[6] and oceans[7]. The heavy metals in sediment of reservoirs and other water sources may affect the water quality of the sources and do harm to human being's health. Therefore, it will be of great theoretical value and practical importance to assess and predict its potential ecological risk.

In this article, the heavy metals $(\mathrm{Cr}, \mathrm{Cu}, \mathrm{Ni}, \mathrm{Pb}, \mathrm{Zn}, \mathrm{As}, \mathrm{Cd}, \mathrm{Hg})$ in sediment of Biliuhe reservoir were studied. We used the methods of geo-accumulation index and potential ecological risk index to analyze the characteristics of heavy metal pollution in sediment. And grey forecasting model GM $(1,1)$

${ }^{\text {a }}$ Corresponding author : dlhongbo@126.com 
and RBF neural network were applied to predict the risk value of the heavy metals in sediment, in order to provide the theoretical basis for the management of the reservoir in the future.

\section{Research Methods}

\subsection{Geo-accumulation index}

Geo-accumulation index ( $\left.I_{g e o}\right)$ originally was introduced by Muller[8] (1979) in order to determine and define metal contamination in sediments by comparing current concentrations with pre-industrial levels. Geo-accumulation index can be used as a reference to estimate the extent of metal pollution. Muller had distinguished seven classes of the geo-accumulation index from Class 0 to Class 6 . The specific classification was as shown in table 1 .

Table 1. Pollution level of heavy metals based on index of geo-accumulation

\begin{tabular}{|c|c|c|c|c|c|c|c|}
\hline \multirow{2}{*}{ Items } & \multicolumn{7}{|c|}{$I_{\text {geo }}$} \\
\cline { 2 - 7 } & $\leq 0$ & $(0 \sim 1)$ & {$[1 \sim 2)$} & {$[2 \sim 3)$} & {$[3 \sim 4)$} & {$[4 \sim 5)$} & $\geq 5$ \\
\hline Class & 0 & 1 & 2 & 3 & 4 & 5 & 6 \\
\hline $\begin{array}{c}\text { Pollution } \\
\text { index }\end{array}$ & Clean & $\begin{array}{c}\text { Slight } \\
\text { pollution }\end{array}$ & $\begin{array}{c}\text { Partial } \\
\text { moderate } \\
\text { pollution }\end{array}$ & $\begin{array}{c}\text { Moderate } \\
\text { pollution }\end{array}$ & $\begin{array}{c}\text { Partial } \\
\text { heavy } \\
\text { pollution }\end{array}$ & $\begin{array}{c}\text { Heavy } \\
\text { pollution }\end{array}$ & $\begin{array}{c}\text { Serious } \\
\text { pollution }\end{array}$ \\
\hline
\end{tabular}

\subsection{Index method of potential ecological hazard}

We used potential ecological hazard evaluation toward contents of heavy metals in sediment of Biliuhe reservoir through adopting the evaluation method of sediment pollution which was put forward by Hakanson[9]. Table 2 was the level of ecological risk of single pollutant and partition criterion of level of comprehensive potential ecological risk, where $E_{i}$ is the coefficient of potential ecological hazard of single heavy metal and RI is the hazard index of potential ecological risk of many kinds of heavy metals.

Table 2. Single and comprehensive indexes and grades of potential ecological risk assessment

\begin{tabular}{|c|c|c|c|}
\hline$E_{i}$ & $\begin{array}{c}\text { The degree of single potential } \\
\text { ecological risk }\end{array}$ & RI & $\begin{array}{c}\text { The degree of comprehensive } \\
\text { potential ecological risk }\end{array}$ \\
\hline$E_{i}<40$ & Low & $\mathrm{RI}<150$ & Low \\
\hline $40 \leq E_{i}<80$ & Medium & $150 \leq \mathrm{RI}<300$ & Medium \\
\hline $80 \leq E_{i}<160$ & Partial heavy & $300 \leq \mathrm{RI}<600$ & Heavy \\
\hline $160 \leq E_{i}<320$ & Heavy & $\mathrm{RI} \geq 600$ & Serious \\
\hline $320 \leq E_{i}$ & Serious & & \\
\hline
\end{tabular}

\subsection{The grey forecasting model GM $(1,1)$}

Time series prediction conducts the trend prediction principle, in the year of 1982, Chinese scholar Professor Deng put forward the Grey System Theory for the first time[10]. The theory is used to study the uncertain problems whose quantities of data are not enough and the information is scarce. Table 3 showed the model precision criteria[11], where $p$ is the small error probability and $\mathrm{C}$ is the posterior variance ratio. 
Table 3. The precision criteria of grey forecasting model GM(1,1)

\begin{tabular}{|c|c|c|}
\hline Model precision class & $p$ & C \\
\hline Class 1---Good & $\geq 0.95$ & $\leq 0.35$ \\
\hline Class 2---Qualified & $0.80 \sim 0.95$ & $0.35 \sim 0.5$ \\
\hline Class 3---Reluctant & $0.70 \sim 0.80$ & $0.5 \sim 0.65$ \\
\hline Class 4---Unqualified & $<0.70$ & $>0.65$ \\
\hline
\end{tabular}

\subsection{The RBF neural network model}

In 1988, RBF neural network was used for the design of artificial neural network by Broomhead, Moody and Darken for the first time, since then the RBF neural network was born[12]. The structure of RBF neural network is a kind of three-layer fully deficient network which is similar to the structures of many other BP networks. The first layer is the input layer which is mainly composed of source nodes. The second layer is the hidden layer, the number of its units depends on different situations. The last layer represents the output layer, which plays the role in response to the input terminal.

\section{Results}

\subsection{Heavy metal pollution assessment}

According to practical situation, this paper used geo-accumulation index and potential ecological risk index to evaluate the pollution of heavy metals in sediment. From the figure 1, we could see that from the three water periods, the class of geo-accumulation index of $\mathrm{Cu}$ and $\mathrm{Hg}$ was 1 and others were 0 . Overall, the class of geo-accumulation index of all heavy metals in sediment of Biliuhe reservoir was less than or equal to 1 , and the class of geo-accumulation index of $\mathrm{Cu}, \mathrm{Ni}, \mathrm{Pb}, \mathrm{Zn}$ and $\mathrm{Hg}$ also achieved the transformation from mild contamination to clean from plentiful water period to common water period then to dry period, which stated the heavy metals in sediment had fewer influence on Biliuhe reservoir and most reached the clean level.
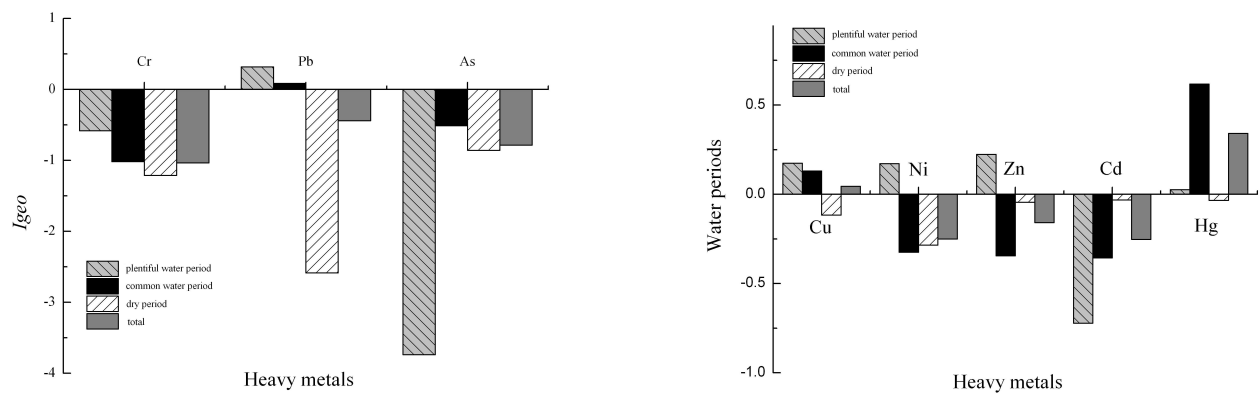

Figure1. The indexes of geo-accumulation in sediment of Biliuhe reservoir in different water periods

Table 4 was the level of potential ecological risk of each heavy metal that calculated. We could see the level of ecological risk of single pollutant of $\mathrm{Hg}$ was medium and the level of ecological risk of single pollutant of other heavy metals was low, and the level of comprehensive potential ecological risk of heavy metal in sediment of Biliuhe reservoir was low, which did not threaten ecological environment of reservoir. But in consideration of that the level of ecological risk of single pollutant of 
$\mathrm{Hg}$ in three water periods was higher than other heavy metals and reached the middle level, it should be paid more attention.

Table 4. $E_{i}$, RI and risk grades in sediment from the Biliuhe reservoir

\begin{tabular}{|c|c|c|c|c|c|c|c|c|c|}
\hline \multirow{2}{*}{$\begin{array}{c}\text { Water } \\
\text { periods }\end{array}$} & \multirow{2}{*}{ Items } & \multicolumn{8}{|c|}{ Heavy metals } \\
\hline & & $\mathrm{Cr}$ & $\mathrm{Cu}$ & $\mathrm{Ni}$ & $\mathrm{Pb}$ & $\mathrm{Zn}$ & As & $\mathrm{Cd}$ & $\mathrm{Hg}$ \\
\hline \multirow{4}{*}{$\begin{array}{c}\text { Plentiful } \\
\text { water } \\
\text { period }\end{array}$} & $E_{i}$ & 2.003 & 8.460 & 8.447 & 9.346 & 1.752 & 1.125 & $\begin{array}{c}27.27 \\
3\end{array}$ & 61.081 \\
\hline & $\begin{array}{l}\text { The degree of } \\
\text { single potential } \\
\text { ecological risk }\end{array}$ & Low & Low & Low & Low & Low & Low & Low & $\begin{array}{l}\text { Med- } \\
\text { ium }\end{array}$ \\
\hline & $\mathrm{RI}$ & \multicolumn{8}{|c|}{119.487} \\
\hline & $\begin{array}{c}\text { The degree of } \\
\text { comprehensive } \\
\text { potential ecological } \\
\text { risk }\end{array}$ & \multicolumn{8}{|c|}{ Low } \\
\hline \multirow{4}{*}{$\begin{array}{c}\text { Common } \\
\text { water } \\
\text { period }\end{array}$} & $E_{i}$ & 1.482 & 8.207 & 5.986 & 7.956 & 1.181 & $\begin{array}{c}10.53 \\
1\end{array}$ & $\begin{array}{c}35.16 \\
8\end{array}$ & 92.054 \\
\hline & $\begin{array}{l}\text { The degree of } \\
\text { single potential } \\
\text { ecological risk }\end{array}$ & Low & Low & Low & Low & Low & Low & Low & $\begin{array}{l}\text { Med- } \\
\text { ium }\end{array}$ \\
\hline & RI & \multicolumn{8}{|c|}{162.565} \\
\hline & $\begin{array}{c}\text { The degree of } \\
\text { comprehensive } \\
\text { potential ecological } \\
\text { risk }\end{array}$ & \multicolumn{8}{|c|}{ Medium } \\
\hline \multirow{4}{*}{$\begin{array}{c}\text { Dry } \\
\text { period }\end{array}$} & $E_{i}$ & 1.294 & 6.919 & 6.159 & 1.250 & 1.454 & 8.278 & 44 & 58.595 \\
\hline & $\begin{array}{l}\text { The degree of } \\
\text { single potential } \\
\text { ecological risk }\end{array}$ & Low & Low & Low & Low & Low & Low & $\begin{array}{c}\text { Med- } \\
\text { ium }\end{array}$ & $\begin{array}{c}\text { Med- } \\
\text { ium }\end{array}$ \\
\hline & RI & \multicolumn{8}{|c|}{127.949} \\
\hline & $\begin{array}{c}\text { The degree of } \\
\text { comprehensive } \\
\text { potential ecological } \\
\text { risk }\end{array}$ & \multicolumn{8}{|c|}{ Low } \\
\hline \multirow{4}{*}{ Total } & $E_{i}$ & 1.463 & 7.738 & 6.305 & 5.519 & 1.345 & 8.700 & $\begin{array}{c}37.76 \\
9\end{array}$ & 76.008 \\
\hline & $\begin{array}{l}\text { The degree of } \\
\text { single potential } \\
\text { ecological risk }\end{array}$ & Low & Low & Low & Low & Low & Low & Low & $\begin{array}{l}\text { Med- } \\
\text { ium }\end{array}$ \\
\hline & RI & \multicolumn{8}{|c|}{144.847} \\
\hline & $\begin{array}{c}\text { The degree of } \\
\text { comprehensive } \\
\text { potential ecological } \\
\text { risk }\end{array}$ & \multicolumn{8}{|c|}{ Low } \\
\hline
\end{tabular}

\subsection{The risk prediction of heavy metals in sediment.}

Xiaolong Shang, Haiyan $\mathrm{Yu}[13,14]$ et al. have studied the migration and transformation of some environmental factors on the heavy metals in water, these processes are affected by $\mathrm{pH}, \mathrm{TN}$, TP, water temperature, DO and other environmental factors in the water environment while the influence degree varies. Considering some general monitoring indicators such as temperature, $\mathrm{pH}, \mathrm{TN}, \mathrm{TP}$ and DO have different influence on the algae in the water[15], then affect the migration and transformation of the heavy metals in water and sediment, and have further influence on the contents of heavy metals in 
sediment, therefore, in this study we selected water temperature, $\mathrm{pH}, \mathrm{TN}, \mathrm{TP}$ and DO these five basic indicators to predict the contents of heavy metals in sediment of Biliuhe reservoir.

This paper adopted the grey forecasting model GM $(1,1)$ and used the annual average of $\mathrm{pH}, \mathrm{TN}$, $\mathrm{TP}$, DO in water of Biliuhe reservoir in recent five years from 2010 to 2014 to predict the concentrations of $\mathrm{pH}, \mathrm{TN}, \mathrm{TP}, \mathrm{DO}$ in the water of Biliuhe reservoir in the year of 2015 . The results were shown in Table 5. We used the annual average water temperature in the reservoir as the data in the year of 2015 due to the data of the water temperature was not fully count and the changing trend of the water temperature was not obvious over the years. The accuracy of the grey model is usually examined by the posterior variance method, the reference indexes are the posterior variance ratio and the small error probability. We could see from table 5 and table 3 that the prediction model accuracy of $\mathrm{pH}, \mathrm{TN}, \mathrm{TP}, \mathrm{DO}$ in water of Biliuhe reservoir in the year of 2015 all could be used. It presented that the predictive values were relatively accurate combining with the relative error values.

Table 5. The predictive value of grey forecasting model $\operatorname{GM}(1,1)$

\begin{tabular}{|c|c|c|c|c|}
\hline & $\mathrm{pH}$ & $\mathrm{TN}$ & $\mathrm{TP}$ & DO \\
\hline $\begin{array}{c}\text { The predictive } \\
\text { value in } \\
2015 /\left(\mathrm{mg} \cdot \mathrm{Kg}^{-1}\right)\end{array}$ & 8.35 & 3.69 & 0.025 & 9.07 \\
\hline $\begin{array}{c}\text { The relative } \\
\text { error/(\%) }\end{array}$ & 0.94 & 22.09 & 14.56 & 4.30 \\
\hline $\begin{array}{c}\text { The small error } \\
\text { probability } p\end{array}$ & 1 & 1 & 1 & 0.8 \\
\hline $\begin{array}{c}\text { The posterior } \\
\text { variance ratio C }\end{array}$ & 0.3962 & 0.4126 & 0.3768 & 0.5656 \\
\hline
\end{tabular}

According to the factors that influence heavy metal contents in sediment of Biliuhe reservoir, this paper confirmed that the numbers of input layer of establishing RBF neural network were five: $\mathrm{pH}$ $\left(X_{1}\right)$, TN $\left(X_{2}\right)$, TP $\left(X_{3}\right), \mathrm{DO}\left(X_{4}\right)$ and water temperature $\left(X_{5}\right)$, which respectively represented the body of water of Biliuhe reservoir during 2015 and 2016; the numbers of hidden layer would automatically adjust through neural network learning process; while the number of output layer was 1 , it represented the contents of heavy metals $\left(y_{l}\right)$ in sediment of Biliuhe reservoir. There were eight kinds of heavy metals which needed to be predicted, thus it needed to establish eight kinds of RBF neural network which took different heavy metals as output units.

RBF neural network learning method belongs to supervised learning and the quantity of samples directly influences the effect of network training. This article adopted linear interpolation[16] to carry out balance interpolation about samples and each two groups of samples inserted into five values, forming 199 groups of samples and randomly selected 160 groups of heavy metals in sediment of Biliuhe reservoir during 2014 and 2015 as training samples of RBF neural network to carry out artificial network training; adopting the rest of 39 groups to proceed verification of network. In the process of neural network training, average relative error of eight neural network models was between $2.53 \%$ and $7.70 \%$ and in the process of verification, average relative error of models was between $3.04 \%$ and $8.04 \%$, which were all lower than $10 \%$, stating that eight RBF neural network models had good precision on the simulation of output result, which could be used as the prediction of heavy metal content in sediment of Biliuhe reservoir.

We brought the predicted values of $\mathrm{pH}, \mathrm{TN}, \mathrm{TP}, \mathrm{DO}$ and water temperature in the body of water in 2015 into corresponding RBF model and selected geo-accumulation index and potential ecological hazard index as evaluation indexes to forecast heavy metals in sediment of reservoir during 2015 to 2016. The results obtained were shown as table 6, it could be seen that $I_{\text {geo }}$ of $\mathrm{Hg}$ in the heavy metals in sediment of Biliuhe reservoir during 2015 to 2016 was first level and lied in the condition of mild contamination, $E r$ was 89.838 and had heavier ecological risk. The $I_{g e o}$ of other heavy metal indexes were 0 , which lied in clean condition, the $E r$ of $\mathrm{Cr}, \mathrm{Cu}, \mathrm{Ni}, \mathrm{Pb}, \mathrm{Zn}, \mathrm{As}$ and $\mathrm{Cd}$ respectively was 1.189 , $7.068,5.359,5.832,1.177,12.648$ and 33.545, which was at low ecological risk. Comprehensive potential ecological risk value RI of the whole reservoir area was 156.66 and lied in medium level of 
risk, and the growth of RI mainly was from the increase in the content of $\mathrm{Hg}$, the government should pay more attention to publish some effective preventive measures.

Table 6. The predicted results of RBF neural network

\begin{tabular}{|c|c|c|c|c|c|c|c|c|}
\hline Heavy metals & $\mathrm{Cr}$ & $\mathrm{Cu}$ & $\mathrm{Ni}$ & $\mathrm{Pb}$ & $\mathrm{Zn}$ & $\mathrm{As}$ & $\mathrm{Cd}$ & $\mathrm{Hg}$ \\
\hline Content $/\left(\mathrm{mg} \cdot \mathrm{Kg}^{-1}\right)$ & 34.41 & 27.99 & 27.44 & 24.96 & 74.74 & 11.13 & 0.123 & 0.0831 \\
\hline$I_{\text {geo }}$ & -1.34 & -0.086 & -0.48 & -0.36 & -0.35 & -0.25 & -0.42 & 0.58 \\
\hline Class & 0 & 0 & 0 & 0 & 0 & 0 & 0 & 1 \\
\hline Contamination index & Clean & Clean & Clean & Clean & Clean & Clean & Clean & $\begin{array}{c}\text { Slight } \\
\text { pollution }\end{array}$ \\
\hline$E r$ & 1.189 & 7.068 & 5.359 & 5.832 & 1.177 & $\begin{array}{c}12.64 \\
8\end{array}$ & $\begin{array}{c}33.54 \\
5\end{array}$ & 89.838 \\
\hline $\begin{array}{c}\text { The degree of single } \\
\text { potential ecological risk }\end{array}$ & Low & Low & Low & Low & Low & Low & Low & $\begin{array}{c}\text { Partial } \\
\text { heavy }\end{array}$ \\
\hline$R I$ & \multicolumn{8}{|c|}{156.66} \\
\hline $\begin{array}{c}\text { The degree of } \\
\text { comprehensive potential } \\
\text { ecological risk }\end{array}$ & \multicolumn{8}{|c|}{ Medium } \\
\hline
\end{tabular}

\section{Conclusions}

1) From the assessment of heavy metals in sediment, the results were similar with the two assessing methods---geo-accumulation index and potential ecological risk index. The pollution level of the heavy metal in sediment of Biliuhe reservoir was not heavy. The geo-accumulation indexes of $\mathrm{Cu}$ and $\mathrm{Hg}$ were higher than other heavy metals, and the ecological risk of $\mathrm{Hg}$ was the highest among the heavy metals in sediment, $\mathrm{Hg}$ was the main monitoring indicators in the future.

2) As the forecasting results of the heavy metals in sediment of Biliuhe reservoir during 2015 to 2016, Hg had a higher pollution level than others, which increased the potential ecological risk of the whole reservoir. The risk value of $\mathrm{Hg}$ was high in 2014 2015, and the predicted results of the degree of risk had an increasing tendency. The government should pay more attention to publish some effective preventive measures. The models will be used widely in the field of ecological risk assessment of heavy metals in sediment, due to the simplification and maneuverability of them.

\section{References}

1. Pekey H. Heavy metal pollution assessment in sediments of the Izmit Bay, Turkey[J]. Environmental Monitoring and Assessment, 2006, 123(1-3): 219-231.

2. Fan M J, Yuan X Z, Zhu H N, et al. Assessment model for heavy metal pollution in river sediment based on triangular fuzzy numbers[J]. Acta Scientiae Circumstantiae, 2010, 30(8): 1700-1706.

3. Wang Y, Liu R, Fan D, et al. Distribution and accumulation characteristics of heavy metals in sediments in southern sea area of Huludao City, China[J]. Chinese geographical science, 2013, 23(2): 194-202.

4. Jiang M, Ruan H H, Mei W P, et al. On the ecological risk assessment and the principal cpmponent analysis of heavy metals in the sediments of Dishui Lake[J]. Journal of Safety and Environment, 2013, 13(3): 151.

5. Jiang Y, Liu X, Gao J F, et al. Pollution characteristics and potential ecological risk assessment of heavy metals in surface sediments of shallow lakes in Jiangsu Province, China[J]. Resources and Environment in the Yangtze Basin, 2015, 24(07): 1157-1162.

6. Lu J L, Hao L B, Zhao Y Y, et al. Contents and potential ecological risk of heavy metals in middle and lower reaches of second Songhua River[J]. Environmental Science \& Technology, 2009, 32(5): 168-172. 
7. Cai H Q, Du Q, Qian X M, et al. Analysis on source of heavy metals and transitional element in maine sediment in the Sansha bay of Fujian[J]. Acta Geologica Sinica, 2007, 81(10): 1444-1448.

8. Muller G. Index of geoaccumulation in sediments of the Rhine River[J]. 1969.

9. Hakanson L. An ecological risk index for aquatic pollution control. A sedimentological approach[J]. Water research, 1980, 14(8): 975-1001.

10. Deng J L. Gray forecast and decision-making [M]. Press of Huazhong University of Science and Technology, 1986.

11. Zhang H F, Lu Y X. Grey theory and neural network combination model in the application of the water quality prediction[J]. Water \& Wastewater Engineering, 2010, 36(1).

12. Schilling R J, Carroll Jr J J, Al-Ajlouni A F. Approximation of nonlinear systems with radial basis function neural networks[J]. Neural Networks, IEEE Transactions on, 2001, 12(1): 1-15.

13. Shang X L, Yu H P, Chen P Q, et al. The Impact of water environmental factors on the migration and transformation of heavy metals of $\mathrm{Cu}, \mathrm{Pb}, \mathrm{Cd}$ in Le' an River and Poyang Lake[J]. Journal of Jiangxi Normal University (Natural Science), 2014, 38(6): 650-655.

14. She H Y. Introduction of the absorption - desorption of heavy metal in the sediment of rivers and lakes[J]. Chemical Engineer, 2005 (7): 30-33.

15. Wang J, Chen J Z, Meng S L. The effects of environmental factors on the growth and competition of algae[J]. Chinese Agricultural Science Bulletin, 2013, 29(17): 52-56.

16. Chen L H, Ma S Q, Li L. A model to evaluate do of river based on artificial neural network and stylebook[J]. Journal of Hainan Normal University (Natural Science), 2008, 21(4): 372-376. 